\title{
As vias (e as vozes) do afeto
}

\author{
Jacques Fontanille \\ https://orcid.org/0000-0003-1141-1596 \\ I - Université de Limoges \\ Limoges, França
}

Resumo: $\mathrm{O}$ artigo analisa os diversos tratamentos do afeto no campo das pesquisas semióticas abertas por Greimas. Ele mostra as premissas, seus desenvolvimentos, seus desaparecimentos e seus ressurgimentos e, mais geralmente, as complementariedades e as derivações solidárias. Em Semântica estrutural, Greimas lançava já algumas bases como a categoria tímica e a proprioceptividade. Muito mais tarde, a teoria das paixões reencontrará a tensividade, e Claude Zilberberg fará do afeto o ponto de origem de toda tensividade. Segue a contribuição de Eric Landowski, que, tratando da experiência vivida, torna obsoleta a distinção entre paixões lexicalizadas e "paixões sem nome". Também serão mencionadas as proposições de Jacques Geninasca, Herman Parret e, mais recentemente, de Waldir Beividas. Mas insistiremos sobretudo sobre a via desenvolvida pelo próprio Greimas em De l'Imperfection, a partir da experiência estética na própria existência.

Palavras-chave: afeto; paixão; provar; tensividade; timia; foria.

Abstract: Ways and Voices of the Affect - The article analyses the different treatments of affect in the field of semiotic researches opened by Greimas. It highlights the premises, their developments, their disappearances and their resurgences, and more generally the complementarities and solidary derivations. In Sémantique Structurale, Greimas already posed some milestones with the thymic category and proprioceptivity. Much later, the theory of passions will encounter tensiveness, and Claude Zilberberg will even make affect the point of origin of all tensiveness. Then arrives the contribution of Eric Landowski, who, under the heading of "feeling" (I'éprouver), renders obsolete the distinction between lexicalized passions (nameable) and "passions without names". The proposals of Jacques Geninasca, Herman Parret and more recently Waldir Beividas will also be evoked. But above all we shall insist on the path developed by Greimas himself in De I'Imperfection, starting from the esthetic experience in existence itself.

Keywords: affect; passion; feeling; tensiveness; thymic dimension; phoric dimension.

\section{Por que o afeto?}

Nos anos sessenta do século passado, o lugar da substância no campo de análise linguística e semiótica era muito reduzido e aceitava-se, em geral, dar a preeminência, ou 
mesmo a exclusividade, à forma. O "afeto" era concebido, nesse período do estruturalismo triunfante, como parte da substância, seja a substância da expressão, com as variações rítmicas, melódicas e acentuais da fala viva, seja a substância do conteúdo, com os diferentes tipos de emoções, de estados de alma e de sentimentos.

Isso não significa que a análise não levava em consideração a dimensão afetiva dos textos e de outros tipos de semioses, mas que ela não era apreendida em si mesma: essa dimensão só era considerada indiretamente e em razão de sua contribuição à forma semiótica. O paralelo com a expressão sonora se impõe: quando a análise fonológica chega a tratar da forma linguística, os fonemas e seus traços distintivos, e, ainda mais, as categorias abstratas que os constituem, não possuem mais nada de "sonoro". Do mesmo modo, quando a análise semiótica destaca a forma de uma transformação narrativa poderosamente sustentada por encadeamentos e conflitos passionais, ela não "vê" mais a especificidade da dimensão afetiva, mas apreende a respeito dela somente uma estrutura abstrata livre de todas as dimensões da substância.

Consequentemente, buscar as vias do afeto pode se efetuar por duas direções complementares: (1) seja a de um acesso do afeto e das paixões ao universo das formas, e não somente das substâncias; (2) seja a constituição de um outro movimento de pesquisa semiótica, que levaria em consideração a substância e que, por esse meio, reencontraria o afeto. Como se verá, as apostas da abordagem greimasiana da dimensão afetiva se jogam na confrontação e na complementariedade dessas duas vias.

\section{Como o afeto aflora em Semântica estrutural}

Os comentaristas da obra de Greimas situam o surgimento da teoria das paixões após a teoria das modalidades, no final dos anos setenta, o que pressupõe que nada teria permitido prever esse aparecimento em suas obras anteriores. No entanto, a dimensão afetiva não está totalmente ausente do seu primeiro trabalho, Semântica estrutural (GREIMAS, 1966). Antes de esboçar o desdobramento dessa teoria e de suas diversas derivações, faremos um pouco de arqueologia greimasiana.

Efetivamente, as questões relativas à afetividade aparecem pública e explicitamente no percurso da pesquisa de Greimas, pela primeira vez e sob o nome de "paixões", em seu seminário na École des Hautes Etudes en Sciences Sociales, no final dos anos setenta: após dois anos consagrados às modalidades, vieram outros dois anos dedicados às paixões. Poder-se-ia pensar que nada permitia prever essa evolução e que ela só pode ser explicada pelos efeitos indiretos da pesquisa sobre as modalidades: é, de fato, nessa ocasião que, se apoiando na distinção entre "modalidades do fazer" e "modalidades do ser", Greimas propõe limitar as primeiras ao campo da ação e explorar as últimas para desenvolver uma semiótica das paixões. Ele retomará essa proposição em Sobre o sentido II (2014), no qual explicita, em especial, uma conversão decisiva para a compreensão 
das paixões: a conversão entre a "massa tímica" (dividida entre euforia e disforia), de um lado, e as modalidades do ser (desejável, indispensável, inútil, etc.), que caracterizam as relações afetivo-modais entre sujeitos e objetos, ou, se se preferir, as propriedades modais e passionais de qualquer interação.

O afeto, contudo, não está totalmente ausente das preocupações do autor em Semântica Estrutural. Em primeiro lugar, ele propõe "considerar a percepção como o lugar não linguístico onde se situa a apreensão da significação" (GREIMAS, 1966, p. 8) e continua admitindo que, desse modo, "A semântica se reconhece abertamente como uma tentativa de descrição do mundo das qualidades sensíveis" (ibid., p. 9). Greimas não fala de afeto, mas a ancoragem fenomenológica dessa sua tomada de posição, sob a autoridade de Merleau-Ponty, implica que as descontinuidades significantes são o produto de nossa atividade perceptiva, isto é, da maneira como experimentamos o "mundo das qualidades sensíveis". Por princípio, essa experiência é em si indivisível: a apreensão das descontinuidades é, portanto, inseparável do afeto elementar que ela suscita. Poder-se-ia provavelmente até considerar que o afeto é mesmo essa apreensão. Essa cena original da apreensão do sentido se completará pouco a pouco, sem que, por isso, o discurso da análise semântica focalize diretamente esse hipotético afeto elementar.

O apagamento voluntário do afeto em Semântica estrutural se explica facilmente e é justificado várias vezes no livro. Por exemplo, à propósito do método de Gilbert Durand, Greimas rejeita a noção de "esquema", isto é, os gestos e as experiências somáticas elementares que suscitam as grandes oposições arquetípicas - cuja natureza é, em parte, passional - , como pertencentes a "distinções operadas ao nível extralinguístico" (GREIMAS, 1966, p. 56). Greimas imediatamente lembra que "O semiológico é, como a linguagem em geral, apreensível dentro da percepção e não deve nada à realidade exterior»(ibid.). O gesto e a experiência somática, portanto, não participariam da percepção semiológica, embora concorram para estruturar a experiência que fazemos das descontinuidades qualitativas.

Greimas explica como e por que ele procede desse modo. Em relação à transformação do corpus em texto, ele detalha as operações do que ele chama de "normalização" e, em particular, a eliminação das categorias que comportam um "parâmetro de subjetividade", a saber: as da pessoa, do tempo relativo ao nunc, da dêixis em geral e da dimensão fática. Escapam por pouco dessa normalização as modalidades (com alguma hesitação) e o aspecto (com maior hesitação ainda). A afetividade nem sequer é mencionada, mas seentende que ela também depende, implicitamente, das categorias "subjetivas" que se deve eliminar. O procedimento de redução é, assim, o principal componente do dispositivo que permite realizar a "objetivação" do texto a partir do corpus.

Nessas condições, é tentador reexaminar os momentos de emergência do afeto em Semântica estrutural como uma dimensão contida e deliberadamente reduzida, e que, no entanto, aflora na argumentação. 
No desenvolvimento dedicado à isotopia, Greimas aponta, por exemplo, o papel da propriocepção:

Dir-se-ia que tudo se passa como se, ao nível da percepção onde situamos essas figuras, uma categoria subjetiva, proprioceptiva, viesse a seu encontro para binarizálas numa espécie de a priori integrado na própria percepção (1966, pp. 86-87).

Tudo já está dito aí: a propriocepção inclui um parâmetro "subjetivo". Segue um comentário sobre o papel da distinção entre euforia e disforia, os dois polos da timia (GREIMAS, 1966, p. 116). O corpo sensível e sua proprioceptividade, uma vez reduzidos à timia, poderiam reintegrar a apreensão perceptiva da significação. Em suma, sob esta condição de redução à categoria tímico-proprioceptiva, a experiência somática (cf. supra) e o afeto poderiam ser reconhecidos como participantes da percepção das descontinuidades semânticas. Primeiro afloramento, seguido do primeiro recalcamento: imediatamente, o universo semântico é dividido exclusivamente entre dois tipos de classemas: $E$ para Exteroceptividade (a dimensão dita "cosmológica") e I para Interoceptividade (a dimensão dita "noológica"). Saí, assim, o eventual classema $P$, para Proprioceptividade, que nunca mais será evocado.

Pouco depois, são as condições do "vivido" que afloram: no estudo da manifestação discursiva e, mais precisamente, dos "microuniversos semânticos", Greimas tenta, com efeito, especificar sob quais condições se poderia pensar em uma apreensão simultânea de todos os elementos constitutivos de um universo de significação (uma "percepção sincrônica", ele escreve [GREIMAS, 1966, p. 127]). Para isso, partindo da necessária segmentação do discurso em frases e partes coerentes e apreensíveis, ele extrapola a noção mais geral de "microuniverso". Os microuniversos semânticos resultam da "explosão" do universo semântico em geral, em vista de uma adaptação aos limites da apreensão perceptiva e às restrições da discursivização. Eles geralmente são organizados em torno de um predicado e de seus actantes. Além disso, eles são os únicos produtos da segmentação (a "explosão") do universo semântico que sejam suscetíveis de ser "percebidos, memorizados e 'vividos'" (idem). Mas a constituição interna desses microuniversos, que poderia explicar porque eles podem ser "vividos", é descartada, e uma tipologia geral se constitui: apagamento provisório do "vivido" e da experiência direta e imediata das montagens sêmicas denominadas de "microuniversos".

Greimas, no entanto, retornará posteriormente à estrutura interna desses "microuniversos semânticos", por meio da reflexão sobre actantes e predicados. Ele já observa o "caráter modal" das categorias actanciais, o qual participa do caráter "espetacular" dos microuniversos semânticos: 
microuniversos semânticos, cujos conteúdos (...) não constituem senão variáveis (GREIMAS, 1966, p. 133).

O caráter modal dos actantes será explicitado mais tarde, mas, nesse ponto do raciocínio, ele inspira uma digressão surpreendente: a dimensão modal dos microuniversos semânticos e os modos de existência que ela caracteriza e distingue, dependeriam da epistemologia linguística. Greimas comenta: "a estrutura da mensagem impõe uma certa visão do mundo" (1966, p. 133). Daí a perspectiva de uma tipologia dos modos de existência, que seria "uma tipologia dos espetáculos assim constituídos" (idem) e igualmente uma tipologia das "condições linguísticas do conhecimento do mundo" (ibidem).

Quando Greimas, em Semântica estrutural, evoca os "modos de existência", ele não visa nem principalmente nem explicitamente ao que eles mais tarde se tornarão, a saber, a série virtual, atual, potencial, real. Ele visa, mais geralmente, à inflexão existencial que produz uma coloração modal particular das interações entre os actantes. A hipótese subjacente é que nossa apreensão sensível do universo semântico (na percepção, ele diz) descobre um "espetáculo" actancial, e que a significação desse espetáculo só pode ser apreendida através da identificação de uma modalidade dominante (saber, poder ou querer). Essa modalidade dominante instaura, então, um "modo de existência" específico: cognitivo, potestativo ou volitivo.

Essa é precisamente a via aberta por Etienne Souriau em seu estudo Les différents modes d'existence (SOURIAU, 2009). Para ele, os modos de existência são induzidos por inflexões da experiência que podem ser de natureza modal, aspectual ou juntiva. Greimas evocará Souriau a propósito da tipologia dos actantes, mas referindo-se a um outro de seus livros: Les Deux Cent Mille situations dramatiques (SOURIAU, 1950). A propósito dos modos de existência, Souriau não evoca o afeto, mas não está longe disso, uma vez que a instauração dos modos de existência decorre, para ele, da experiência íntima e elementar que fazemos dessas "alterações" (modais, aspectuais etc.) do curso da existência: tratase mesmo de caracterizar a maneira como essas alterações nos afetam na experiência.

Essa relação entre Les différents modes d'existence de Souriau e Semântica estrutural de Greimas, Souriau a propósito dos modos de existência, não terá futuro direto. Mas a questão retornará muito mais tarde em Da Imperfeição (GREIMAS, 2002). O tom é bastante diferente de Semântica Estrutural, mas, em alguns aspectos, são meramente nuances terminológicas: estesia em vez de percepção, desvios do sentido no lugar de modalidades ou ainda mundos em vez de universos. Trata-se sempre, quinze anos depois, de encontrar na experiência sensível os desvios que são a chave para mundos significantes alternativos, isto é, modos de existência semiótica diferentes.

É, portanto, a reflexão sobre os actantes que suscita regularmente, em Semântica estrutural, o afloramento do afeto. Já ao examinar a possibilidade de transformar funções narrativas redundantes em qualificações dos actantes, Greimas nota, por exemplo, que a iteração da função "ele se salvou" autoriza sua transformação em qualificação ("medo"), 
bem como a iteração de funções que comportam modalidades como "'saber' ou 'poder' as transformam em qualidades permanentes" (GREIMAS, 1966, p. 165). Pouco depois, mencionando o investimento temático dos actantes, ele reproduz a lista das forças temáticas de Souriau, que são inteiramente formuladas em termos afetivos e passionais: a tematização dos actantes seria, portanto, de natureza passional. Greimas reduz esse inventário à distinção "obsessão vs. fobia", referindo-se finalmente ao "conteúdo semântico quer do actante-sujeito quer do actante-objeto, que pode ser-lhes atribuído por outros procedimentos, notadamente pela análise qualificativa" (GREIMAS, 1966, p. 182). Em seguida, concluirá, após a redução das funções proppianas:

Sem ousarmos nos pronunciar, por enquanto, sobre a natureza da correlação entre os valores que constituem a aposta da narrativa e as categorias modais constitutivas do modelo actancial, a existência desta correlação traz a confirmação do caráter de grande generalidade que possuem tanto uns quanto outras (GREIMAS, 1966, p. 209)

É precisamente a partir dessa correlação — a articulação entre os valores narrativos e as qualificações modais dos actantes — que, «ousando se pronunciar», Greimas desenvolverá posteriormente sua teoria das paixões. É precisamente ao retornar à distinção "obsessão / fobia", reformulada nos termos da categoria tímica, que ligará a polarização dos valores narrativos, por um lado, e a modalização do espetáculo actancial, por outro. O desvio ou a inflexão modal "afeta" e orienta (positiva ou negativamente) a experiência sensível e essa orientação em si inflecte os valores narrativos envolvidos nas relações entre actantes.

\section{Da semiótica da ação à semiótica das paixões}

\subsection{A objetivação da forma semiótica das paixões}

A possibilidade de acessar à forma semiótica das paixões já está, portanto, em gestação nas reflexões sobre os microuniversos semânticos, sobre sua organização actancial e sua coloração modal. A forma em questão se constituirá na intersecção, já identificada em Semântica estrutural, entre os valores narrativos e as relações interactanciais modalizadas.

O primeiro artigo de Greimas que deixa entrever a possibilidade de uma semiótica das paixões, isto é, "Sobre a modalização do ser" (GREIMAS, 2014, pp. 79-101), estabelece a distinção entre a competência modal do sujeito narrativo e a sua existência modal. É o resultado final do que ele contemplava em Semântica estrutural: a transformação das funções redundantes em qualificações permanentes. A categoria das "modalidades de ser" (dever-ser, querer-ser, poder-ser etc.) é definida em relação a uma outra mais profunda que não pertence à esquematização narrativa: a "foria" (o que leva em direção a...). As duas categorias reenviam à mesma substância (elas são homólogas), mas não têm a mesma forma (são heteromórficas). A conversão de uma em outra é obtida pela divisão da foria em 
várias dimensões modais: é assim que os dois polos da foria, a euforia e a disforia, serão rearticulados nas respectivas variedades do querer-ser (desejável / indesejável), do dever-ser (indispensável / nocivo), do poder-ser (possível / impossível) etc[AMB2] [MOU3] [MOU4] .

Essa proposição permite o acesso à forma passional sem reintroduzir o "parâmetro de subjetividade" que Greimas tentava eliminar. A forma passional se situa, de fato, na interseção entre os conteúdos modais que definem os estados afetivos dos sujeitos, os processos de valorização axiológica e a "massa tímica": a foria, que é dada pelo conteúdo formal elementar resultante da propriocepção, por um lado, polariza os sistemas de valores e, por outro, produz, por divisão e conversão, as modalidades de existência (ou existência modal).

Mas a objetivação (e, em particular, a redução de tudo o que está sujeito às condições da enunciação e às posições subjetivas) proibia a vinculação com o que estava paralelamente se desenvolvendo na linguística — a linguística enunciativa elabora, com efeito, um componente afetivo dentro do que se denomina modalização enunciativa - e também na semiologia. Barthes, em Fragmentos do discurso amoroso (2003), procede exatamente no sentido oposto: pouca consideração pela forma dada ao afeto, ainda menos por seus componentes semânticos, mas, ao contrário, uma enunciação passional que se desenrola em cenas sucessivas:

\begin{abstract}
Substituímos pois a descrição do discurso amoroso por sua simulação e devolvemos a esse discurso sua pessoa fundamental, que é o eu, a fim de pôr em cena uma enunciação, não uma análise. É um perfil, por assim dizer, que está sendo proposto; mas esse perfil não é psicológico; é estrutural: oferece à leitura um lugar de palavra, o lugar de alguém que fala em si mesmo, amorosamente (...) (BARTHES, 2003, p. XVII).
\end{abstract}

Pode-se entender que essas considerações sobre a enunciação possam ser mantidas de lado, enquanto se trata apenas da organização semântica dos percursos narrativos objetivados. Ao contrário, a análise das paixões, que implica a propriocepção e a timia, e, portanto, o papel do corpo na semiose e sua enunciação, exerce uma pressão crítica sobre o princípio da objetivação metodológica e desencadeia soluções alternativas as quais retornaremos.

O próprio Greimas muda pouco a pouco o ângulo de abordagem: sem renunciar ao fundamento modal das paixões, ele se questiona mais precisamente sobre a paixão como uma sequência e propõe algumas análises sintagmáticas que parecem diretamente derivadas da reflexão sobre o caráter espetacular dos "microuniversos" de Semântica estrutural: por exemplo, a da cólera, cujos três segmentos - "frustração", "descontentamento", "agressividade" (GREIMAS, 2014, pp. 233-253) - são cenas de interação nas quais aparece uma dimensão modal constante que orienta o encadeamento: a espera fiduciária. Mas a análise dessa dimensão modal revela uma nova propriedade das modalidades: 
elas não só semantizam os actantes (e "colorem" um modo de existência), mas também os implicam em uma tensão que exige resolução. A confiança é um investimento actancial complexo, constituído ao mesmo tempo por um crer e uma espera, ou seja, um constituinte modal, por um lado, e um expoente tensivo, por outro. Consequentemente, o percurso das interações entre actantes se estende entre a atualização da tensão e sua resolução: no caso da cólera, a resolução é uma explosão, um gasto imediato de energia, em detrimento da retenção e da paciência que seriam necessárias para uma vingança.

As tensões em questão são propriedades do processo e não do sistema. Elas podem ser derivadas das modalidades, com a condição que estas últimas sejam consideradas não apenas como classemas cujo único papel seria unificar as cenas predicativas dos microuniversos semânticos, mas também como quantum de energia potencial, que sustenta o processo em curso de finalização. A questão então se desloca: esses fenômenos tensivos só devem ser considerados inerentes à manifestação e à discursivização? Ou eles já pertencem também ao sistema imanente, cuja concepção deve, então, ser revisada?

\subsection{A solução tensiva}

Em Semiótica das paixões (GREIMAS e FONTANILLE, 1993), a tensividade apresenta-se primeiro como uma propriedade comum a um conjunto de categorias que agora parecem, ao lado das modalizações, necessárias à descrição das paixões: a aspectualização dos processos (como no caso da cólera), mas também a intensidade e a quantidade, que estruturam toda a dimensão afetiva. A tensividade não pode, portanto, aparecer no último momento da discursivização. É preciso, assim, prever seu lugar na imanência.

A tensividade torna-se, por essa razão, o correlato indispensável da foria. A reunião dos dois permite, então, avançar o conceito de espaço tensivo-fórico, no qual as précondições da significação seriam definidas e onde o sentir mínimo estaria situado. Se, desde Semântica estrutural, a percepção é o lugar não linguístico onde são apreendidas as descontinuidades da significação, o sentir será, a partir de Semiótica das paixões, o lugar não linguístico (ou "pré-semiótico") onde essas descontinuidades são de início experimentadas como tensões do sentido.

Para Zilberberg e Fontanille, em Tensão e significação (2001), a tensividade pode ser dividida em duas categorias concorrentes e solidárias, cujas relações estão no próprio princípio das variações da tensividade. Uma é a intensidade: a força, a energia, o afeto. A outra é a extensão: quantidade, desdobramento, espaço e tempo, cognição.

\subsection{A energia e a intensidade}

A intensidade tem como correlato fenomenológico a proprioceptividade, a sensibilidade do corpo próprio que serve de mediador entre os dois planos da semiose. 
A intensidade pertence assim ao classema $\mathrm{P}$, cuja evocação e imediato recalcamento em Semântica estrutural já assinalamos. Mas ela não pode ser reduzida dessa maneira, em razão, por um lado, de seu caráter gradual, que se presta mal a uma análise classemática, e, por outro, por causa da substância a qual ela dá forma, a das energias do corpo próprio, que dependeria, antes, da "massa tímica" e da foria. A propriocepção é uma das dimensões da percepção semiótica, e só se pode integrar nela as energias e a sua intensidade, redefinindo o papel dessa percepção: ela só apreenderia, então, as descontinuidades da significação ao experimentar (previamente? paralelamente? consecutivamente?) as tensões (e em particular as flutuações da intensidade) a partir das quais elas emanam.

A semiótica tensiva vai ainda mais longe, especialmente na versão desenvolvida por Claude Zilberberg, que reduz as descontinuidades a desequilíbrios extremos nas tensões entre intensidade e extensão. Assim, ele opõe os valores de absoluto aos valores de universo:

Um valor que combina uma intensidade extrema com uma extensidade reduzida à unidade, será chamado de absoluto. (...) O um sendo único, os valores de absoluto afirmam o brilho, o termo supremo das visadas mais elevadas (ZILBERBERG, 2011, p. 18)

$\mathrm{Na}$ análise dos percursos passionais e, em particular, do agenciamento das modalidades que os subtendem, deve-se prever o papel dessas energias do corpo próprio, que distribuem intensidades variáveis ao longo da cadeia das modalizações. Por exemplo, a análise de uma reação impulsiva evidenciará uma distribuição desigual da intensidade na série querer, poder, saber. Essa reação se caracteriza pela sua imediaticidade, de modo que nenhuma deliberação (saber) a precede, que a passagem ao ato nem sequer pode ser atribuída a uma decisão (querer) e pode até ser considerada involuntária. Por si só, o movimento reativo, carregado de uma intensa capacidade de agir (o poder-fazer), é suficiente. Assim, a intensidade marca, pela sua força ou pela sua fraqueza, cada um dos constituintes da cadeia sintagmática, de modo que alguns se tornam constituintes regentes e outros regidos.

\subsection{A extensão e a quantidade}

A quantidade intervém de duas maneiras complementares na forma semiótica das paixões. Primeiro, e sobre o fundo das primeiras sugestões feitas em Semântica estrutural, o número de ocorrências (em termos de funções narrativas, cenas predicativas ou de acontecimentos e de estados) é um componente da qualificação passional dos actantes: é necessária uma certa recorrência ou uma certa duração da "fuga" para que se possa inferir o "medo" e, mais ainda, o papel "medroso". Já se observou que Greimas assinalou, na lista de forças temáticas de Souriau, a omnipresença da "obsessão" (e seu correlativo negativo, a "fobia"): ambas implicam a iteração e até mesmo uma iteração que se mantém sob a pressão de uma intensidade (a «força», segundo Souriau). 
Mas a relação entre quantidade e intensidade pode ser invertida: entre orgulho e susceptibilidade, a intensidade da reação passional se enfraquece, ao mesmo tempo em que o número de ocorrências aumenta: o orgulho é expresso apenas na ocasião de um pequeno número de acontecimentos cujo caráter disfórico é julgado particularmente intenso, enquanto a susceptibilidade se apreende em todas as ocasiões, cuja intensidade é imperceptível e cujas ocorrências são em geral imprevisíveis. Nesse caso, quanto mais a iteração é numerosa, mais a intensidade é fraca. Do mesmo modo, a avareza pode se exercer sobre um único objeto, intenso e compacto (um patrimônio, um tesouro etc.), enquanto a mesquinhez impõe uma acumulação sistemática de objetos em que nenhum, por si mesmo, mobiliza separadamente uma forte intensidade.

A quantidade contribui para a análise das paixões sob uma segunda forma, e sob o controle da intensidade: essa forma é a da coesão de um todo constituído por partes. $\mathrm{Na}$ iteração, seja de predicados, seja de sujeitos, seja de objetos, a percepção das tensões semânticas deve encontrar um princípio unificador, um princípio mereológico. Isso porque os afetos, devido à distribuição desigual e variável da intensidade, prejudicam a estabilidade das identidades no percurso passional e as reconfiguram permanentemente. A distribuição dos afetos dissocia ou aglomera modalidades, intensifica um papel e suspende outros, ou reúne os papéis em torno de um, entre outras possibilidades. A paixão seria essa ligação mais ou menos eficaz que garante a consistência do todo e, especialmente, do espetáculo da cena predicativa que Greimas tinha identificado em Semântica estrutural. A natureza das totalidades envolvidas nos processos passionais e, em particular, o seu momento de unidade, constitui, sem dúvida, um dos mais belos objetos de pesquisa (e um dos mais inesperados) para a semiótica das paixões.

\subsection{Intensidade e extensão}

Intensidade e extensão são os componentes semânticos da tensividade. Esses dois componentes são indissociáveis, ou seja, eles pressupõem um ao outro e, portanto, eles se reforçam ou se enfraquecem reciprocamente. Claude Zilberberg (2011) toma, a esse respeito, duas posições que merecem ser discutidas. A primeira consiste em afirmar que a intensidade rege a extensão e, consequentemente, a precede na constituição da categoria geral "tensividade". A segunda consiste em considerar apenas as situações em que a intensidade e a extensão se combatem e evoluem solidariamente em sentido inverso, isto é, em excluir a tensão de convergência para reter apenas a tensão de inversão.

A primeira dessas posições, a preeminência da intensidade, é assim fundada: "Para a semiótica tensiva, as grandezas intensas são da ordem dos afetos e, como tal, elas regem as grandezas extensas" (ZILBERBERG, 2011, p. 8). Claude Zilberberg afirma em seguida:

A tensividade, portanto, não tem um lugar próprio: ela é apenas o lugar de encontro, o ponto de fusão, a linha de frente onde a intensidade se apodera da extensidade, 
onde um plano do conteúdo intensivo se une a um plano de expressão extensivo. A própria teoria se torna uma semiose (ZILBERBERG, 2011, p. 9).

Essa posição, que é sedutora devido à simplificação que traz ao dispositivo teórico, poderia até mesmo ser consensual, uma vez que coloca o sensível e o afeto do lado das grandezas regentes (a intensidade) e a inteligibilidade e cognição do lado das grandezas regidas (a extensão). Seria então compatível com a direção que o próprio Greimas havia estabelecido em Da Imperfeição, que coloca a estesia como ponto de partida para a constituição dos modos de existência semiótica. Também seria compatível com as propostas de Landowski, cuja análise das interações privilegia igualmente a apreensão na experiência, no vivido sensível e afetivo do encontro, da aléa e do ajustamento.

Com o risco de passarmos por menos consensual, devemos, no entanto, questionar as implicações epistemológicas de tal escolha. O problema que se coloca, nos próprios termos da Semântica estrutural, é a organização da percepção semiótica, um "lugar não linguístico" onde as articulações da significação são apreendidas. Como assinalamos anteriormente, trata-se de precisar quais são as relações (de determinação e de recção) entre a percepção das descontinuidades, por um lado, e a das tensões, por outro. Podemos até acrescentar: em nome do que o sensível e o afeto dependeriam apenas da intensidade? Para esboçar uma resposta, nos referimos ao trabalho de Jean-François Bordron, cuja contribuição é indispensável para entender o que está acontecendo nesse lugar semiótico, mas não linguístico, que é a percepção.

No capítulo "Iconicité" de seu livro L'iconicité et ses images, Bordron começa por observar que o ponto de partida da abordagem estruturalista é o postulado de que "existem substâncias e fluxos aos quais se pode dar forma" e que a significação é a formatação dessas substâncias e desses fluxos-força (BORDRON, 2011, p. 157). Mas o movimento de formatação pode partir de dois aspectos ontológicos, entre os quais Bordron não escolhe: uma composição de entidades autônomas, que devem estar relacionadas como partes descontínuas e chamadas a constituir uma totalidade, ou uma composição de fluxos e forças, cujos princípios de regulação devem ser identificados para constituir um processo globalmente inteligível.

Na concepção desenvolvida por Bordron, e inspirada em Kant, é o momento da apreensão que permite identificar com o que o movimento de composição terá de lidar: a apreensão é da ordem da constatação da existência (há alguma coisa que afeta a percepção), e essa "alguma coisa" pode ser tanto um conjunto de partes-entidades descontínuas como um conjunto de fluxos-força a ser regulado ou, mais frequentemente, ambos ao mesmo tempo. É assim, nesse momento de apreensão (Greimas também evocou, em Semântica estrutural, a percepção que "apreende" a significação) que podem ser identificados, quer descontinuidades entre entidades, quer fluxos e tensões entre forças e suas direções, ou ainda a mistura indissociável dos dois. 
O momento seguinte, aquele que "iconiza", é o da composição propriamente dita e de sua estabilização. O terceiro momento será o da simbolização, que projeta "regras" sobre os resultados do segundo momento, ou seja, sobre a composição icônica. De acordo com o princípio da análise estrutural, a composição busca e estabiliza dependências. Do lado das entidades descontínuas (o primeiro caso ontológico), trata-se de dependências livres: segundo Bordron, as dependências são livres "quando as partes de um todo podem ser concebidas independentemente umas das outras" (BORDRON, 2011, p. 168). Do lado dos fluxos e forças (segundo caso ontológico), são dependências ligadas que, de acordo com Bordron, "unem entre elas as partes de um todo quando essas partes não podem ser concebidas umas sem as outras" (idem). As dependências livres estariam, portanto, do lado das descontinuidades, e as dependências ligadas do lado da continuidade.

O tratamento das dependências ligadas é de inspiração tensiva: Bordron propõe, ao invés de uma simples duplicação entre intensidade e extensão, uma triplicação: a quantidade (matéria), a qualidade (intensidade) e a relação (forma). O princípio é tensivo, embora em um sentido um pouco diferente do que ocorre na semiótica tensiva, na medida em que essas três categorias só podem evoluir uma em relação à outra, mas mantendo alguma autonomia. Ao contrário, o tratamento das dependências livres é de inspiração mereológica. Retomando seu artigo fundador, "Les objets en parties", Bordron (1991) distingue vários tipos de totalidades, segundo os diferentes tipos de ligações que associam suas partes: as configurações, as arquiteturas, as aglomerações, as redes e as fusões (BORDRON, 2011, p. 174).

Voltemos ao nosso problema inicial: o que vem primeiro? A percepção de forças intensivas? Ou a percepção das descontinuidades extensivas? Ambas solicitam às vezes uma apreensão sensível e uma construção inteligível. Se questionarmos a percepção semiótica, seguindo Bordron, toda decisão a esse respeito seria inspirada por uma escolha ontológica, uma vez que seria necessário decidir não entre dois modos de construção semiótica (na fase 2), mas inicialmente entre dois modos de apreensão sensível das ontologias subjacentes (na fase 1). Os modos de composição e de estruturação decorrem dos modos de apreensão: a construção semiótica não escolhe entre os dois modos de apreensão, ela os sucede, coleta os resultados e Ihes dá forma'.

1 Podemos comparar essas reflexões, inspiradas pela semiótica da percepção de Bordron, com as primeiras formulações da semiótica da experiência de Landowski: "Dependendo das circunstâncias, em função dos contextos, dos tipos de objetos que se apresentam e da natureza das relações que procuramos estabelecer com aquilo que nos rodeia, oscilamos constantemente, na própria vida, entre pelo menos duas maneiras muito diferentes de olhar o mundo e de fazê-lo significar. Em termos um pouco mais abstratos, diremos que se trata de dois regimes de significância ao mesmo tempo distintos e complementares e cujas características respectivas são diretamente em relação, por um lado, com as do 'discurso da narração', e, por outro, com as do 'vivido da experiência'. No contexto de uma problemática semiótica que se quer de alcance geral, ambos os regimes devem ser levados em consideração. De acordo com o primeiro, olhamos para o mundo como se se tratasse de uma superfície de inscrição coberta de signos que teríamos aprendido a ler. Nossa compreensão do mundo passa então pela decifração das formas manifestas que, verbais ou não, constituem o equivalente de textos que 'querem dizer' algo. Ao contrário, de acordo com o outro regime, não olhamos mais, ou não ainda, o mundo como uma rede de signos a decifrar. Não há então nada para decifrar, nada para ler, nenhum texto. E, porém, já existe, paradoxalmente, sentido e valor. Isso porque, à falta de identificar na superfície das coisas marcas de discursos inteligíveis que nos seriam endereçados, nos deixamos então impregnar pelas qualidades sensíveis inerentes às próprias coisas cuja presença nos cerca» (LANDOWSKI, 2007, pp. 26-43). 
Decidir, como faz Zilberberg, que a intensidade e o afeto são "regentes" é, portanto, uma escolha de horizonte ontológico, da qual deriva uma semiótica inteira, marcada por essa opção. A semiótica estrutural de Greimas tinha, dos anos sessenta aos anos oitenta, feito a escolha do outro horizonte ontológico: o das descontinuidades.

Seria possível imaginar uma semiótica futura que, como a abordagem empreendida por Bordron, não faria nenhuma escolha ontológica prévia, mas que, em vez disso, estaria interessada na instauração de ontologias múltiplas e complexas, criadas pela coabitação, pela competição ou pela colusão entre os dois modos de estruturação e de composição: o das grandezas descontínuas e das composições mereológicas; e o das grandezas contínuas, energéticas e fluentes? Isso sempre parece possível, pois a escolha ontológica que estamos discutindo é quase sempre, para aqueles que a fazem, uma premissa não discutida. Em Greimas, a escolha das descontinuidades é devolvida ao "inventário epistemológico dos postulados não analisados" (GREIMAS 1966, p. 28). Essa escolha é acompanhada por um comentário muito moderadamente entusiasmado:

O único modo de abordar, atualmente, o problema da significação consiste em afirmar a existência de descontinuidades, e a de diferenças pertinentes (...), sem se preocupar com a natureza das diferenças percebida (GREIMAS, 1966, p. 18, nossos grifos).

Zilberberg, fazendo a escolha inversa quarenta e cinco anos depois, não se preocupou com nenhuma precaução. Para situar a tensividade de um ponto de vista epistemológico, apelou para Cassirer e comentou:

A tensividade não tem, portanto, conteúdo próprio. (...) trata-se mais de uma protolinguagem, como sugere Cassirer: "Sem o fato de que um sentido se manifesta em certas vivências perceptivas, a existência permaneceria muda para nós". Tudo se passa como se o enunciado fundador enunciasse: No início era o afeto... (ZILBERBERG, 2011, p. 9)

De fato, "far-se-á como se" vivido = afeto = intensidade.

Tanto Greimas como Zilberberg se referem à percepção do sentido. O primeiro afirma que, naquele momento, apenas o que é percebido como descontínuo deve ser retido, ao passo que o segundo afirma intemporalmente que tudo o que é percebido é de ordem afetiva. A análise sistemática dessa percepção semiótica, como Bordron a conduz, nos incita a pensar que cada um retém apenas metade das percepções semióticas. Em suma, a escolha ontológica não é nem necessária nem desejável: a articulação entre essas duas maneiras de apreender o sentido, e com algumas outras que, sem dúvida, ainda serão descobertas, é uma das principais tarefas de uma semiótica que desejaria ser realmente "geral". E, à procura dessas articulações, quer sejam oposições ou tensões, triagens ou misturas, chegaríamos, como faz Landowski, construindo pacientemente os seus regimes de 
sentido (LANDOWSKI, 2014), a uma visão propriamente estrutural dos modos de existência que dão forma aos diferentes tipos de mundos nos quais se produzem as semioses.

Se a segunda posição, aquela de Zilberberg, relativa à exclusão das tensões de convergência entre a intensidade e a extensão, tem um alcance menor, os seus inconvenientes não são menores que os da primeira. Notamos primeiro que ela nunca é discutida e decidida: trata-se de uma exclusão de fato e implícita, sem qualquer justificativa que não seja seu uso recorrente. Em segundo lugar, o que se exclui é, no entanto, relevante, no âmbito da própria semiótica tensiva, e atestado na análise concreta. Tomemos o exemplo da distinção entre valores de absoluto e valores de universo: esses carregam todo o brilho da intensidade, ao preço de uma drástica redução da extensão (e, em particular, do número das adesões que eles atraem); aqueles se beneficiam da extensão e de uma difusão máximas, ao preço de um enfraquecimento radical da intensidade. A estrutura tensiva assim concebida tem a seguinte forma:

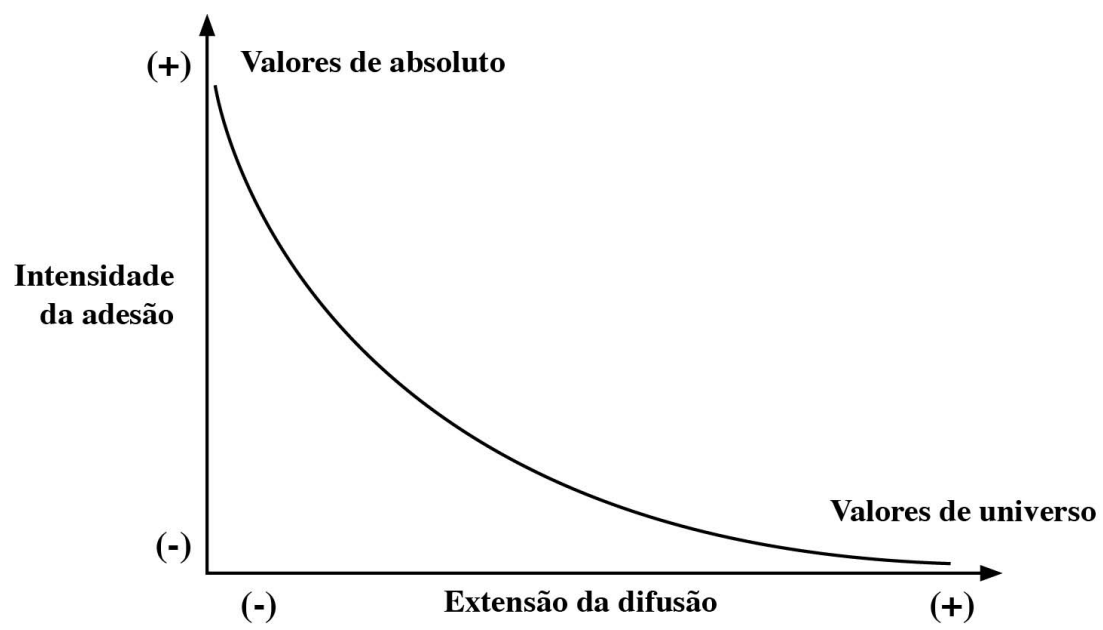

Desse modo, são excluídos os seguintes valores: 1) os valores que poderiam ser qualificados de "valores de distinção", de baixa intensidade e difusão restrita; e 2) os valores universais que logram uma forte adesão coletiva. O modelo assim reduzido não prevê, portanto, nenhum lugar para as adesões frágeis e individuais, digamos "marginais", nem para as adesões maciças e intensas. Por exemplo: não haveria nenhum lugar nesse modelo reduzido para o movimento dos "Indignados", na Espanha, ou para as grandes manifestações nacionais que ocorreram na França após os ataques terroristas. Ao reintroduzir esses dois outros tipos de valores, que se baseiam na convergência das mudanças respectivas da intensidade e da extensão (enfraquecimento ou reforço convergentes nas duas dimensões), devemos redistribuir os valores de universo em dois tipos: por um lado, valores universais, de adesão forte e maciça, e, por outro lado, 
os simples valores de partilha, amplamente difundidos, mas fracamente assumidos. O diagrama tensivo abaixo se beneficia dessa redistribuição.

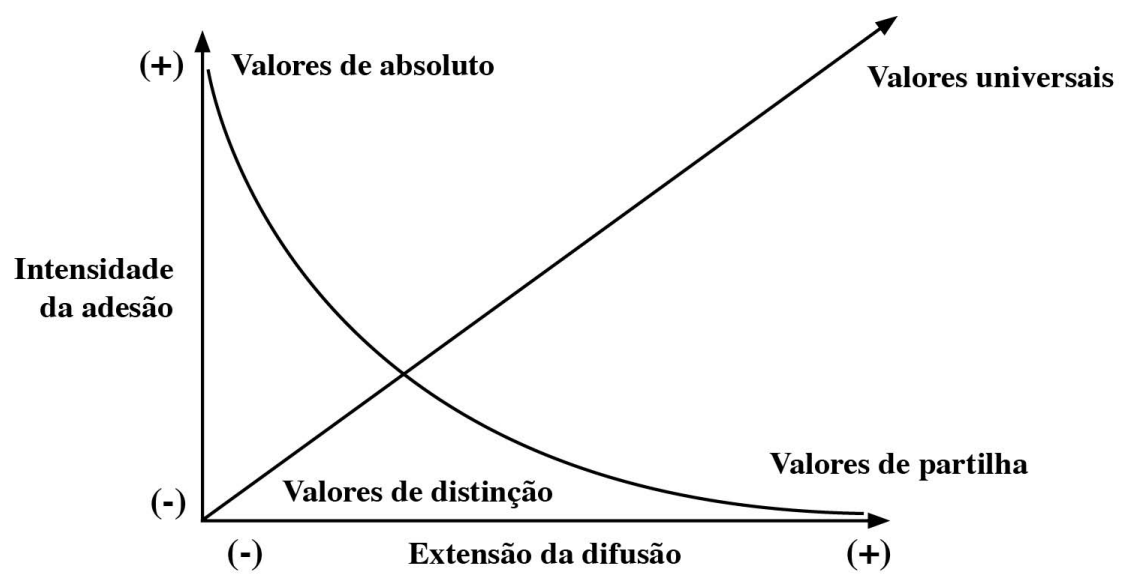

O exemplo dos tipos de valores é apenas um entre muitos casos: a análise tensiva de qualquer categoria, a partir do único fundamento da tensão inversa entre intensidade e extensão, é uma perpetuação do binarismo, enquanto a consideração de todas as tensões possíveis entre intensidade e extensão abre o campo para um número maior de variedades. Pode-se também notar, particularmente no que diz respeito aos tipos de valores, que a escolha não discutida de apenas uma das tensões possíveis não deixa de induzir alguns efeitos ideológicos.

Seguindo Greimas, evocamos anteriormente a distinção entre obsessão e fobia no inventário das forças temáticas e passionais de Souriau: são mesmo dois casos em que a intensidade e a força de uma paixão se reforçam pelo número de suas ocorrências. A duração e a frequência são inclusive, aqui, indicações da potência e da profundidade do afeto. As paixões emprestam, portanto, todas as combinações de intensidade e de extensão e se transformam não apenas pelas variações peculiares de cada tipo de tensão (dentro da tensão inversa entre intensidade e extensão ou dentro da tensão conversa), mas também pela variação entre os dois tipos de tensões (passagem da inversão para a convergência e vice-versa). No último caso, por exemplo, a fobia (intensidade e extensão máximas) pode ser reduzida a um susto pontual (intensidade máxima e extensão restrita) ou uma apreensão inquieta (extensão máxima e intensidade fraca).

A arquitetura geral de uma semiótica das paixões desenha-se desse modo, enquanto complemento de uma semiótica da ação:

1) Na superfície do discurso, observam-se dois tipos de manifestações: os afloramentos das variações fóricas e as variações tensivas, nas quais se pode 
distinguir, segundo um princípio já estabelecido por Hjelmslev (1985, pp. 165171), "constituintes" (os segmentos, em uma outra terminologia) e "expoentes" (os fatores "suprassegmentais", também segundo essa outra terminologia). De um lado, os constituintes modais, derivados da foria, e, de outro, os expoentes tensivos, derivados da tensividade. Uns manifestam os estados afetivos por associações de modalidades (poder, saber, querer, dever e crer), outros por variações de intensidade e quantidade discursivas, de aspecto e de ritmo em particular;

2) Em profundidade, as duas dimensões do espaço tensivo-fórico, a tensividade e a foria, resultam globalmente da experiência sensível, da apreensão e da composição respectivas dos fluxos e das forças, por um lado, e das ligações entre partes descontínuas, por outro. A primeira determina as dependências entre a extensão dos fluxos e a intensidade das forças. A segunda decide as dependências entre as totalidades constituídas. A foria, de fato, "leva para" e cria um elo entre as entidades a reunir. Em acepção restrita, ela só diz respeito ao vínculo entre o actante experimentador e o actante experimentado. Na acepção extensa, que consideramos na esteira de Bordron (trata-se das dependências livres), todas as entidades actanciais são levadas em conta, com pelo menos uma delas sendo de natureza subjetiva, para experimentar uma "empatia" em consideração às outras, empatia que a conduz a "fazer ou não fazer parte de...".

\section{Das paixões sem nome e, no entanto, experimentadas}

O conceito de "experimentado" (ou experimentar) aparece no livro de Anne Hénault, Le pouvoir comme passion: trata-se de uma tentativa radical, que parte de um corpus que se presta a (i) destacar uma dimensão passional do discurso que não depende nem da lexicalização da afetividade nem mesmo de uma discursivização explícita da afetividade (ii) para se colocar firmemente na perspectiva de uma semiótica do contínuo e da modulação das intensidades vividas e (iii) apreender, onde quer que aflore linguisticamente, a "vibração íntima" do experimentar (HÉNAULT, 1994).

Hénault adotou resolutamente a perspectiva continuísta dos fluxos e das forças, restringindo as descontinuidades ao domínio da ação e da cognição (HÉNAULT, 1994, p. 4). O significado do "experimentar", ela precisa, é inicialmente "muscular, glandular, epidérmico muito antes de tocar o plano verbal" (ibid., p. 5). Em outras palavras, é o corpo sensível que fornece esses significados. Hénault, além disso, situa as expressões desse experimentar na dimensão suprassegmental do discurso (ibid., p. 8), entendida como o lugar onde ocorre a "captura e até mesmo um contágio de humor" (ibid., p. 10). As ferramentas analíticas (segmentos narrativos e passionais, foria, aspecto, andamento e variação da intensidade) são idênticas às de Semiótica das paixões, mas a diferença reivindicada é essencial: pela primeira vez na pesquisa semiótica sobre paixões, o objeto 
de Henault é o discurso emocional e sensível enquanto tal, e não a reconstrução e a extensão ao discurso de uma paixão-lexema pré-identificada.

Diante de um discurso de aparência impassível (o do Journal de Renault d'Andilly), a análise não pode se apoiar sobre nenhum signo convencional nem qualquer etiquetagem lexical ou sequencial de papéis passionais, de comportamentos ou de estados da alma. A análise deve apreender as menores flutuações da intensidade e da foria, para captar a emergência do passional, onde, antes mesmo da categorização da afetividade em sentimentos e paixões identificáveis, por convenção de gênero ou de interação social, o passional não é admitido. Certamente, a principal paixão pode ser reconhecida (trata-se da ambição e dos efeitos afetivos da competição por honrarias), mas, por ascetismo metodológico, Hénault não concede nenhuma relevância para essa paixão-lexema e se detém na descrição dos efeitos rítmicos e tensivos das flutuações do humor.

A questão que se coloca é, então, a da homogeneidade desses afloramentos passionais e da constituição de um ou mais percursos globalmente homogêneos e significantes. É por isso que o livro se encerra com a abertura de perspectivas mereológicas (cf. supra), relativas à busca do momento de unidade e das totalidades em construção nessa semiótica do contínuo. No geral, e devido às fortes semelhanças entre a concepção desenvolvida por Greimas e a proposta de Hénault, a contribuição desta última parece ainda mais clara: um método de análise dos efeitos textuais do afeto (designado genericamente como o "experimentar") que seja estritamente textual e não para-lexical.

Eric Landowski assume igualmente o conceito de experimentar, que, como se pode ver, substituiu gradualmente o do "sentir", proposto em Semiótica das paixões. Ele o desenvolve sistematicamente e com uma muito grande amplitude, especialmente em Passions sans nom (LANDOWSKI, 2004). No prolongamento das proposições de Da Imperfeição, Landowski faz do experimentar ("éprouver") o processo central da presença no mundo e da experiência vivida dessa presença. Ele precisa e amplia esse conceito: por um lado, o experimentar é um processo que diz respeito tanto ao mundo natural e aos seus objetos, quanto a outros sujeitos, ou seja, a outrem; por outro lado, em um caso como no outro (principalmente no outro), o experimentar é a experiência sensível de uma interação. Em suma, para experimentar, é necessário "fazer sociedade": fazer sociedade com o mundo natural, com os objetos e, claro, com outros sujeitos.

Nessa perspectiva, o que os semioticistas se acostumaram a chamar de "paixões" com Greimas torna-se difícil de isolar: Landowski lembra que na perspectiva das interações e das experiências que fazemos, o encontro dos corpos, a confrontação com outrem, a estesia e os afetos que isso produz, e até mesmo as ações e reações que resultam, são inseparáveis (LANDOWSKI, 2004, pp. 8-11). Inseparáveis, as paixões em questão também são, na maior parte dos casos, sem nome: demasiadamente fugazes, sujeitas a variações incessantes, elas apenas raramente cumprem as condições que permitiriam a uma cultura e a uma língua reconhecer nelas estados e qualificações duráveis e estáveis dos actantes.

Landowski então distancia-se da semiótica das paixões desenvolvida por Greimas por 
meio de um argumento que pode ser resumido dessa maneira (LANDOWSKI, 2004, pp. 3949): apesar de eles declararem que a ligação entre o sensível e o inteligível é indissolúvel, os autores de Semiótica das paixões não se dão os meios (conceituais e metodológicos) para tratar realmente desse «híbrido» indissociável. Por um lado, eles privilegiam as paixões da ruptura, deixando de lado as flutuações afetivas cotidianas e, por outro, mantêm os princípios de uma análise derivada da semiótica da ação, em particular a análise modal.

Ele propõe como alternativa uma semiótica da união (e não da junção), que se caracteriza principalmente por um processo muito original (e talvez um pouco otimista) de produção do sentido (LANDOWSKI, 2004, pp. 89-92): o sentido está imediatamente presente no sensível, ele surge dos corpos em interação e em co-construção e, mais precisamente, da capacidade desses corpos para transmitir efeitos de sentido por contágio (inter-corporal). A configuração da união pressupõe, na experiência sensível, uma interação global e, a princípio, corporal. A união implica, como modo de semiose, o contágio do sentido, e ela adota, como forma do processo, equivalente à prática enunciava desse sentido, o ajustamento entre os actantes.

O encontro entre os actantes, que são então apenas puras potencialidades, supõe uma abertura e uma disponibilidade recíprocas: do lado do sujeito da experiência (o experimentador), essa disponibilidade para o outro coincide com a instauração de um "si"; e do lado do mundo, do outro ou do objeto (o experimentado), a disponibilidade para o contágio que se prepara toma a forma de uma coesão, de uma consistência, feita de dependências e correspondências internas que indicam a via para uma possível totalização. Nesse processo de co-construção dos actantes, os corpos recebem marcas uns dos outros, que permitem inscrever o processo no tempo e no aspecto (pontual, durativo, iterativo etc.) das interações (LANDOWSKI, 2004, pp. 125; 136). A longo prazo, elas contribuem para a instauração em uns e outros de disposições duráveis e de habitus, trazidos pelo corpo sensível (idem, pp. 150-158). Em suma, nos processos de ajustamento, é preciso compor a regulação dos fluxos e das forças com a estruturação das partes em totalidades (cf. supra).

As marcas do corpo sensível também podem ser consideradas a partir de dois pontos de vista complementares: do ponto de vista do ato que os inscreve e daquele do actante que recebe essas inscrições.

Jacques Geninasca enfatizou particularmente o ato, que ele chama de apreensão impressiva (1997). Pode-se apenas abordar esse conceito com grande cautela, pois Geninasca o usa sem defini-lo de forma explícita e sistemática. Ele dedica atenção considerável à definição dos outros dois tipos de apreensões, a apreensão molar e a apreensão semântica, em longos desenvolvimentos nos quais a oposição entre os dois parece cobrir o conjunto dos fatos e fenômenos para descrever (idem, pp. 59-64; 88-91). A apreensão molar, que participa de uma racionalidade prática, dá lugar a uma semiótica (monoplanar) do signo-referência e privilegia o "fazer referência" e as relações metonímicas. A apreensão semântica participa de uma racionalidade mítica, dando origem a uma semiótica dos conjuntos significantes e privilegia o "significar" e as relações metafóricas. 
A apreensão impressiva não se beneficia de tais precauções conceituais. Inicialmente, ela é referida como "apreensão rítmica" (GENINASCA, 1997, pp. 77-78), por ocasião de uma distinção entre dois tipos de leitura dos "sintagmas seriais": por um lado, uma leitura que evidencia "uma hierarquia de transformações semânticas", por outro lado, uma leitura que leva a

(...) experimentar [o sintagma serial] através de uma série de "acontecimentos" tímicos, dos quais ele fornece o traço perceptível, como a aventura de um sujeito que se reconhece, por e através dos momentos de atividade perceptiva, uma existência "que se basta a si mesma"... (GENINASCA, 1997, p. 77).

Segue a descrição dessa série de acontecimentos tímicos, constituída por esperas e surpresas, por tensões e relaxamentos, e na qual o reconhecimento cognitivo da forma serial é indissociável dos afetos, eufóricos e disfóricos que a ritmam.

A apreensão impressiva está igualmente implicada no "olhar estético" (GENINASCA, 1997, p. 219 et seq.) e evocada (sem ser explicitamente mencionada) na definição de existência modal, na qual o vínculo com a dimensão passional é claramente afirmado:

\begin{abstract}
Designamos por "existência modal" o conjunto das relações de natureza tímica ou patêmica que um Sujeito é suscetível de manter com uma coisa, uma paisagem, uma mulher, uma obra de arte (...). Na medida em que é o lugar de afetos, de sentimentos e de paixões, o Sujeito sente-se existir descobrindo-se incluído num mundo dotado de sentido, cujas figuras, em outras palavras, são sucessivamente modalizadas pelo espanto, o desejo, o medo, a admiração ou a saudade (GENINASCA, 1997, p. 253).
\end{abstract}

Se pudéssemos nos autorizar a reconstituir o mesmo tipo de cadeia conceitual das duas outras apreensões, poderíamos então nos aventurar a dizer que a apreensão impressiva participa de uma racionalidade estética, que dá origem a uma semiótica dos afetos e da existência modal, e que ela privilegia para isso o experimentar das flutuações tensivas e das organizações mereológicas.

O segundo ponto de vista, o do actante que recebe a inscrição das marcas, foi adotado em nosso trabalho, Corpo e sentido, onde o actante narrativo foi reconfigurado em actante-corpo (FONTANILLE, 2016). A teoria das marcas que resulta disso, marcas tanto das interações passadas quanto das interações futuras, repousa em uma composição progressiva entre as figuras semióticas do corpo (corpo-invólucro, corpo-carne, corpoponto, corpo-oco) e os respectivos movimentos típicos de cada uma dessas figuras corporais (deformações, movimentos íntimos, deslocamentos, animação interna).

Os corpos em interação são marcados (por reminiscência ou por antecipação) por - ou em vista de - essas interações. Essas marcações constituem a memória (ou a disposição) figurativa dos actantes-corpos. Podemos então considerar que cada uma das 
composições (figuras corporais e movimentos) origina, por sua vez, tipos de marcas e modos de interpretação: respectivamente, as inscrições e suas decifrações (no corpo-invólucro), os aterramentos sensório-motores e suas extrações (no corpo-carne), as apresentações diegéticas e suas representações (no corpo-oco) e, finalmente, as localizações dêiticas e suas reconstituições em itinerários (pelo corpo-ponto). Já que se trata de marcações e de marcas dos corpos sensíveis, tanto os modos de marcação quanto os modos de interpretação são, por princípio, de natureza passional, e sua dimensão cognitiva (memória, antecipação, reconhecimento, compreensão etc.) é indissociável dos afetos que os motivam e que o corpo experimenta, seja no seu invólucro, em sua carne ou em seu teatro interno, seja em razão de sua posição no mundo.

\section{Paradigmas ou pontos de vista complementares?}

A historiografia "selvagem", e por vezes oportunista, a qual se entrega um bom número de semioticistas, saúda periodicamente, e muitas vezes apressadamente, o surgimento de novos "paradigmas" na pesquisa semiótica em andamento. Em uma forma de vida na qual as tendências na moda e a inovação a todo o custo dominam as mentes e os corpos, a adoção de um novo "paradigma" intelectual é, com efeito, uma oportunidade para se valorizar. Se os semioticistas, enquanto atores engajados nas competições acadêmicas e científicas, podem graças a isso esperar alguns ganhos provisórios de visibilidade, a semiótica, enquanto campo de pesquisa, não está ganhando nisso nem em clareza nem em pertinência. Qualquer um pode até acreditar, de boa fé, que sua contribuição terá um impacto irreversível sobre a economia geral da teoria semiótica, mas, quer isso se verifique, quer não, ninguém pode deduzir que as pesquisas futuras farão dela um paradigma que rompe com os outros e que sua autonomia a longo prazo será reconhecida pela história.

A semiótica das paixões pode num dado momento ser considerada como um novo paradigma, especialmente devido às muitas questões epistemológicas abertas no livro Semiótica das paixões. Mas a maioria dos comentários subsequentes (especialmente os mencionados) mostram que foi sobretudo uma última tentativa para fazer evoluir a semiótica narrativa de Greimas e integrar, em todos os níveis do percurso gerativo, um componente afetivo. A semiótica das paixões, como talvez dirão os futuros historiadores, antes do mais, abriu novos canteiros, que eram até então mais difíceis de abordar sob o olhar crítico e sem complacência de Greimas.

Semiótica das paixões tratava de paixões lexicalizadas ou lexicalizáveis, deixando possível e aberta a exploração de manifestações afetivas não lexicalizáveis: Hénault e Landowski aí encontraram matéria para uma renovação teórica e metodológica. Semiótica das paixões colocava a tensividade e a foria no coração dos desdobramentos afetivos, mas limitando-se ao seu posicionamento epistemológico e sem propor um modelo descritivo 
específico: do lado da tensão, Zilberberg (e Fontanille) escolheram o afeto como base da hipótese tensiva, e do lado da foria (a massa tímica), Bertrand, Fontanille, Geninasca e Landowski projetaram, cada um a seu modo, uma semiótica do corpo sensível e da estesia.

Da mesma maneira, a via aberta por Greimas em Da Imperfeição pode, em um outro momento, ser considerada como o surgimento de um novo paradigma, emprestado sistematicamente por Landowski e, mais ocasionalmente, por muitos outros semioticistas. Na verdade, foi sobretudo o tom e o estilo desse livro que pôde dar uma tal impressão aos leitores, atônitos e confusos com surpresas e desviados por uma escrita que parecia se moldar ao movimento íntimo das obras analisadas. Se Da Imperfeição efetivamente inaugura algo novo nas pesquisas semióticas, é antes de tudo pela possibilidade de escrever semiótica de um outro modo, não à distância, após a objetivação e através da tela da metalinguagem, mas de certo modo em imersão no objeto de análise, uma imersão que permite reencontrar a experiência sensível a partir da qual uma interpretação é possível.

Entretanto, do ponto de vista teórico e em relação aos conceitos mobilizados, essa via de pesquisa estava, como mostramos, já presente na surdina em Semântica estrutural. Nesse livro, ela não estava ausente, mas precisamente recalcada, reduzida pelas operações de normalização. Seu reaparecimento em Da Imperfeição, bem como em muitas considerações epistemológicas em Semiótica das paixões, só prova que o tempo da normalização e da objetivação havia já passado, que o procedimento havia sido provado e tinha dado todos os resultados que se esperava, e que doravante era possível reexaminar, com um novo custo, o que havia sido colocado entre parênteses durante cerca de trinta anos.

Resta considerar as relações entre os desenvolvimentos posteriores. O primeiro entre eles foi proposto por Herman Parret em seu livro intitulado Les passions (PARRET, 1986), que se situa na continuação da hipótese modal conforme formulada por Greimas em Sobre o sentido II. Inteiramente construído sobre a teoria das modalidades, a qual ele acrescenta alguns princípios de concatenação e combinação, o trabalho de Parret não parece abrir uma alternativa à semiótica das paixões.

No entanto, Parret traz à luz, graças ao confronto entre Kant e Hume, no final do qual ele escolhe Kant contra Hume, uma dificuldade relacionada à concepção da foria: a semiótica greimasiana faria a escolha de uma concepção "gravitacional", incluindo atrações e repulsões (os dois polos da foria), que concederia um espaço excessivo aos objetos (que supostamente atraem ou repelem os sujeitos: cf. supra, a nossa definição ampliada da foria), e um espaço insuficiente à constituição da subjetividade (que conteria em si mesma o movimento que a leva em direção a...). É por isso que ele propõe um outro fundamento para as paixões, a empatia (PARRET, 1987, pp. 44-49), que permite submeter "o sistema global das paixões à sua condição de possibilidade, que é a paixão do sujeito por ele mesmo" (idem, p. 44).

Retorno do pêndulo: em oposição a uma semiótica das paixões demasiadamente centrada nos poderes do objeto (objetal, diria Jean-Claude Coquet [2013]), Parret propõe 
uma virada em direção ao pólo sujeito. Um deslocamento da mesma ordem é visado por Waldir Beividas, muito mais recentemente, em um artigo que propõe uma articulação explícita entre a abordagem semiótica das paixões e a abordagem delas pela psicanálise (2016). Ele aponta, com razão, que a semiótica das paixões, em todos os seus desenvolvimentos e em todas as suas derivações conhecidas, manteve a psicanálise cuidadosamente à distância. As razões são numerosas para isso, e mencioná-las detalhadamente aqui seria fora de propósito. Sobre isso, podemos reenviar às precisões dadas no início do artigo de Beividas.

Mas, independentemente das relações com a psicanálise, a proposta de Beividas acentua essa inclinação do pêndulo em direção ao pólo subjetivo, uma orientação apenas esboçada em Parret. Beividas elabora, com efeito, uma proposta muito estimulante de semiotização das pulsões freudianas, no quadro de uma homogeneização da dimensão tímica (e, em particular, de uma neutralização das distinções entre interocepção, exterocepção e propriocepção, em favor do que ele chama de "semiocepção"). Ele precisa, desde o início, que "(...) propomos um modelo baseado na hipótese de que o advento do sujeito pode ser concebido no modo de um percurso (gerativo?) da subjetividade inconsciente. (...) essa hipótese propõe um percurso gerativo da subjetividade (BEIVIDAS, 2016) ${ }^{2}$.

Três regimes constituem os três níveis desse percurso gerativo: (i) um regime pulsional; (ii) um regime patológico; e (iii) um regime passional. O regime pulsional é aquele em que o corpo experimenta valências, pressentimentos, as primeiras tensões do sentido. O regime patológico - que pode ser chamado de pático, no sentido de pathos e não de doença psíquica — é a fase em que a subjetividade humana escolhe ao mesmo tempo seu objeto (de desejo) e sua estrutura patêmica. O regime passional é o que já conhecemos, o das estruturas ou configurações passionais. Beividas comenta: "As paixões humanas, enquanto relações entre sujeitos, seriam, portanto, concebidas como produtos derivados, de segundo grau, a partir das pulsões, através das patologias" (2016).

Não se poderia ser mais claro: depois de ter reduzido a tricotomia exterocepção, interocepção, propriocepção, redução que possibilita o surgimento concomitante de um mundo dos objetos, de um mundo interior dos sujeitos e de um mundo do corpo próprio, permanece apenas um modo de apreensão sensível, ou seja, a semiocepção, e apenas uma fonte possível para os afetos: os sujeitos.

Segundo o campo disciplinar a que se refere no momento da construção semiótica dos afetos e das paixões, a teoria pende de um lado ou do outro: do lado dos objetos e da relação com outrem, quando o horizonte é o da antropologia ou da sociologia (essa é a versão da semiótica das paixões, mas também da semiótica tensiva ou ainda da sociossemiótica em seus desenvolvimentos iniciais), ou do lado do sujeito e de sua elaboração progressiva, quando o horizonte é aquele da filosofia kantiana ou da psicanálise freudiana. Objetivação ou subjetivação: por que dever-se-ia necessariamente escolher?

2 E ele acrescenta: "A questão que aguarda sua resposta aqui é precisamente de ver se as paixões (semióticas) e as pulsões (psicanalíticas) podem ser tornadas compatíveis, na medida em que ambas pertencem ao mesmo universo tímico." (BEIVIDAS, 2016). 
Trata-se de dois pontos de vista complementares, em sentido estrito, e, por conseguinte, eles se impõem uns e outros ao mesmo tempo em que se neutralizam recíproca e alternadamente. Eles se opõem, mas dentro, literalmente, dos mesmos paradigmas.

É exatamente isso o que mostram, por exemplo, Geninasca e Landowski. O primeiro não cessa de insistir, ao acentuar o contraste entre apreensões e racionalidades, sobre o fato de que a maioria dos objetos textuais (principalmente os textos literários) podem ser objeto de diferentes leituras, de acordo com cada uma das três apreensões, e sob o regime de cada uma das três racionalidades. Além disso, ele não propõe nenhuma hierarquia entre as três apreensões e, em particular, a apreensão impressiva não pode de modo algum abrir-se sobre um paradigma autônomo qualquer.

O segundo, Landowski, vai ainda mais longe, fazendo ao mesmo tempo como se o regime de união, de contágio e de ajustamento poderia ter um desenvolvimento definitiva e legitimamente separado: tendo sido o regime da junção abundantemente fundado, ilustrado e argumentado por outra parte, o mínimo que se poderia esperar era que o da união agora retivesse toda a atenção. Mas Landowski vai além de Geninasca, no sentido de que ele propõe, na maioria dos seus modelos, apresentados, na maior parte dos casos, na forma de quadrados semióticos, uma articulação entre os dois regimes, as duas "lógicas": o outro regime, o da junção, da programação e da manipulação faz parte, portanto, em sentido stricto, do mesmo "paradigma" (do mesmo domínio de categorização) que o da união.

Em Presenças do Outro (LANDOWSKI, 2002), ele até desenvolve, sob o modo da junção, e aparentemente sem reticências, políticas de identificação, sob a forma de quadrados que opõem conjunções e disjunções (ibid., p. 50). Ele persiste sob o modo da junção para modelizar os modos de presença de novos lugares para os viajantes que os descobrem (ibid., p. 86). Em Passions sans nom, o regime de união está, com certeza, no primeiro plano, mas sem deixar de permanecer numa relação estreita com o da junção nos mesmos modelos, por exemplo a propósito do sentido e do não-sentido passionais (LANDOWSKI, 2004, p. 51). Além disso, ele frequentemente opõe a perspectiva da apropriação dos objetos, dos outros e do mundo em geral (que decorre da junção), à da realização, do "desabrochamento" ("accomplissement") dos sujeitos, das suas relações e do mundo que eles constroem juntos (que procede da união). Mas isso não impede que, no momento de estabelecer um modelo geral e recapitulativo das formas do "gosto do outro", as manifestações passionais ou sensíveis de ambas as perspectivas se reencontrem nas diferentes posições de um quadrado semiótico comum (ibid., p. 260). Eles se encontram, é claro, em posições opostas, contrárias ou contraditórias, mas são colocados dentro do mesmo campo de categorização (o que é chamado exatamente um mesmo "paradigma").

\section{Para terminar...}

Com o risco de desagradar os amantes da ciência pugilística, o percurso pelos diferentes tratamentos do afeto no campo das pesquisas semióticas abertas por Greimas traz 
à luz sobretudo os fios condutores, as premissas, seus desenvolvimentos, desaparecimentos e ressurgimentos e mais geralmente as complementaridades e derivações solidárias. É indispensável colocar dicotomias teóricas para poder argumentar em planos de imanência homogêneos: por exemplo, diacronia/sincronia em Saussure, ou imanência/ manifestação em Greimas, ou tensão/oposição em Zilberberg, ou finalmente junção/união em Landowski. Essas dualidades não são oposições entre configurações que poderiam estar em contraste no mesmo processo, mas oposições paradigmáticas no sentido estrito, isto é, entre configurações que excluem a presença de uma ou outra no processo (nesse caso, no processo do comentário metassemiótico).

Por conseguinte, elas só podem ser apreendidas segundo pontos de vista complementares. Isso significa que, assim que se adote um ponto de vista em uma dualidade, não se pode mais apreender o que pertence ao outro ponto de vista, que, no entanto, não desaparece, mas permanece potencial e disponível. O conhecimento completo do objeto analisado ou do problema estudado impõe uma articulação de pontos de vista complementares entre eles. Pelo próprio fato de serem dualidades baseadas em oposições paradigmáticas, elas se opõem somente dentro de um paradigma que é comum a elas: para apreender o conjunto do paradigma, é preciso, portanto, poder adotar, alternadamente, os dois pontos de vista. Essa posição foi em particular muito explicitamente defendida por Saussure a propósito da diacronia e da sincronia (SAUSSURE, 1999; 2004). Hoje em dia, cabe a nós apoiá-la em relação às diferentes "vias do afeto" que esboçamos na introdução e retraçamos ao longo deste estudo.

Para retraçar as vias semióticas do afeto, não é, portanto, suficiente relacionar cada uma das vias com uma ou mais vozes, na perspectiva de uma política de conflitos de autoridade científica e legitimidade enunciativa. Pelo contrário, tivemos que reconstituir a estratégia de pesquisa proposta por Greimas: após ter normalizado e objetivado a textualidade narrativa, era preciso, inicialmente, para evitar rupturas imponderadas e inconsequentes, derivar a teoria das paixões a partir da teoria da ação. Relembrar isso basta para explicar a primeira forma adotada pela semiótica das paixões: por um lado, os modelos descritivos e explicativos evoluíram pouco (oposições discretas, quadrado semiótico, sequência patêmica canônica derivada do esquema narrativo canônico) e, por outro, a organização conceitual específica da afetividade "desceu" em profundidade no percurso gerativo, encontrando-se colocada quase à parte, em paralelo, sob a denominação de "pré-condições". Era o preço a pagar para abrir possibilidades de desenvolvimento para a tensividade, o corpo sensível, as flutuações tímicas.

O próprio Greimas, paralelamente à semiótica das paixões, e sem qualquer relação aparente, tratava em Da Imperfeição da experiência estésica na existência e do surgimento de mundos significantes alternativos. O afeto é, então, muito precisamente, o tipo de afeto que é obtido pela experiência das "alterações" da existência vivida, alterações que originam modalizações, mas também muitos outros tipos de "desvios" do sentido. O afeto é o ponto de origem das semioses em formação e, consequentemente, de suas enunciações: a enunciação 
encontra ao mesmo tempo um corpo e uma potência de criação dos "mundos" semióticos. Trata-se, de fato, de uma estratégia de pesquisa diferente daquela da semiótica das paixões, uma vez que a "imperfeição" (um tema genérico para alterações, desvios ou inflexões da existência) é o nome de uma das condições das próprias semioses, e não uma pré-condição do percurso gerativo limitado ao conteúdo. Greimas lamentou, em seus últimos momentos, não poder, ele mesmo, "refazer a semiótica". Outros tentaram... em complementaridade.

Traduzido do francês por Alexandre Marcelo Bueno.

Jacques Fontanille é professor titular da Université de Limoges da qual foi presidente (2005-2012). Criou o Centre de Recherches Sémiotiques (CeReS) e, por mais de vinte anos, dirigiu e foi o principal animador do Séminaire de Sémiotique em Paris. Entre os seus livros destacam-se: Le savoir partagé, Les espaces subjectifs, Sémiotique du visible, Sémiotique du discours. Publicou com Greimas Semiótica das paixões e com Claude Zilberberg Tensão e significação.

jacques.fontanille@unilim.fr

\section{Referências}

BARTHES, R. Fragmentos de um discurso amoroso. Trad. Márcia Valéria Martinez de Aguiar. São Paulo: Martins Fontes, 2003.

BEIVIDAS, W. La sémioception et le pulsionnel en sémiotique. Pour l'homogénéisation de l'univers thymique. Actes Sémiotiques, 119, 2016.

BORDRON, J-F. Les objets en parties. Langages, 103, 1991.

. L'iconicité et ses images. Paris: Presses Universitaires de France, 2011.

COQUET, J-C. A busca do sentido. Trad. Dilson Ferreira Cruz. São Paulo: Editora WMF Martins Fontes, 2013.

FONTANILLE, J. Semiótica do discurso. Trad. Jean Cristtus Portela. São Paulo: Contexto, 2007.

Sémiotique des pratiques. Paris: Presses Universitaires de France, 2008.

. Corpo e sentido. Trad. Fernanda Massi e Adail Sobral. Londrina: Eduel, 2016.

; Zilberberg, C. Tensão e significação. Trad. Ivã Carlos Lopes, Luiz Tatit e Waldir BEIVIDAS. São Paulo: Discurso Editorial: Humanitas/FFLCH/USP, 2001.

GENINASCA, J. La parole littéraire. Paris: Presses Universitaires de France, 1997.

GREIMAS, Algirdas Julien, Sémantique structurale. Paris: Larousse, 1966

Sobre o sentido. Trad. Ana Cristina Cruz Cezar et alli. Petrópolis: Vozes, 1975.

. Sobre o sentido II. Trad. Dilson Ferreira Cruz. São Paulo: Nankin/EDUSP, 2014.

. Da Imperfeição. Trad. Ana Claudia de Oliveira. São Paulo: Hacker Editores, 2002.

; FONTANILLE, J. Semiótica das paixões: dos estados das coisas aos estados da alma. Trad.

Maria José Rodrigues Coracini. São Paulo: Ática, 1993. 
HÉNAULT, A. Le pouvoir comme passion. Paris: Presses Universitaires de France, 1994.

HJELMSLEV, L. La syllabe en tant qu'unité structurale. Nouveaux Essais. Paris: Presses Universitaires de France, 1985.

LANDOWSKI, Eric. A sociedade refletida. Ensaios de sociossemiótica I. Trad. Eduardo Brandão. São Paulo/Campinas: EDUC/Pontes, 1992

Presenças do outro. Ensaios de sociossemiótica II. Trad. São Paulo: Perspectiva, 2002.

Passions sans nom. Essais de socio-sémiotique III. Paris, Presses Universitaires de France, 2004.

2014.

Interações arriscadas. Trad. Luiza Helena O. da Silva. São Paulo: Estação das Letras e Cores,

Unità del senso, pluralità di regimi. In G. Marrone et al. (éds.). Narrazione ed esperienza. Intorno a una semiotica della vita quotidiana. Roma: Meltemi, 2007.

PARRET, H. Les passions. Essai sur la mise en discours de la subjectivité. Liège: Mardaga, 1986.

SAUSSURE, F. de. Curso de linguística geral. Trad. Antonio Chelini, José Paulo Paes e Izidoro Blikstein. São Paulo: Cultrix, 1996.

Escritos de linguística geral. Trad. Carlos Augusto Leuba Salum e Ana Lucia Franco. São Paulo: Cultrix, 2004.

SOURIAU, E. Les Deux Cent Mille situations dramatiques. Paris: Flammarion, 1950.

. Les différents modes d'existence. Suivi de l'CEuvre à faire (précédé d'une introduction « Le sphinx de l'œuvre » par Isabelle Stengers et Bruno Latour). Paris: Presses Universitaires de France, 2009.

ZILBERBERG, C. Essai sur les modalités tensives. Paris-Amsterdam: Benjamins, 1981. 163-204.

Síntese da gramática tensiva. Trad. Ivã Carlos Lopes. Significação, vol. 33, n. 25, 2006, pp.

Des formes de vie aux valeurs. Paris: Presses Universitaires de France, 2011.

Texto recebido em 05/08/2019

e aprovado em 16/10/2019. 